\title{
Increasing blood pressure and its associated factors in Canadian children and adolescents from the Canadian Health Measures Survey
}

\author{
Yipu Shi, Margaret de Groh and Howard Morrison
}

\begin{abstract}
Background: Canada is facing a childhood obesity epidemic. Elevated blood pressure (BP) is a major complication of obesity. Reports on the impact of excess adiposity on BP in children and adolescents have varied significantly across studies. We evaluated the independent effects of obesity, physical activity, family history of hypertension, and socioeconomic status on BP in a nationally representative sample of children and adolescents.
\end{abstract}

Methods: We analysed cross-sectional data for 1850 children aged 6 to 17 years who participated in the Canadian Health Measures Survey, Cycle 1, 2007-2009. Systolic BP (SBP) and diastolic BP (DBP) were age-, sex-, and heightadjusted to z-scores (SBPZ and DBPZ). Body mass index (BMI) Z-scores were calculated based on World Health Organization growth standards. Multivariate linear regression was used to evaluate the independent effects of relevant variables on SBPZ and DBPZ.

Results: For most age/sex groups, obesity was positively associated with SBP. Being obese was associated with higher DBP in adolescent boys only. The BP effect of obesity showed earlier in young girls than boys. Obese adolescents were estimated to have an average $7.6 \mathrm{mmHg}$ higher SBP than normal weight adolescents. BMI had the strongest effect on BP among obese children and adolescents. Moderately active adolescent boys had higher SBP $(3.9 \mathrm{mmHg})$ and DBP $(4.9 \mathrm{mmHg})$ than physically active boys. Family history of hypertension showed effects on SBP and DBP in younger girls and adolescent boys. Both family income and parent education demonstrated independent associations with BP in young children.

Conclusions: Our findings demonstrate the early impact of excess adiposity, insufficient physical activity, family history of hypertension, and socioeconomic inequalities on BP. Early interventions to reduce childhood obesity can, among other things, reduce exposure to prolonged BP elevation and the future risk of cardiovascular disease.

\section{Background}

Between 1978/9 and 2004, the prevalence of obesity among Canadian children aged 2 to 17 years doubled from $6.3 \%$ to $12.7 \%$, while rates of overweight increased from $23.3 \%$ to $34.7 \%$ [1]. One of the major complications of obesity, elevated blood pressure (BP), is found increasingly in Canadian children [2,3]. BP tracks with age and elevated $\mathrm{BP}$ at a young age predicts essential hypertension in adulthood [4]. From a public health perspective, understanding factors associated with increasing BP in Canadian children

\footnotetext{
*Correspondence: yipu.shi@phac-aspc.gc.ca Science Integration Division, Center for Chronic Disease Prevention and Control, Public Health Agency of Canada, 785 Carling Avenue, Ottawa, ON, Canada K1A OK9
}

(c) 2012 Shi et al.; licensee BioMed Central Ltd. This is an Open Access article distributed under the terms of the Creative Commons Attribution License (http://creativecommons.org/licenses/by/2.0), which permits unrestricted use, distribution, and reproduction in any medium, provided the original work is properly cited. can help inform interventions to reduce risks and optimize BP during childhood.

Many studies have shown a positive association between obesity and hypertension in children of various populations [5,6]. The definition of hypertension in children is based on percentile cutoffs from normative distribution of BP in children presumed healthy [7]. There have been concerns that these statistically derived thresholds may underestimate children at risk [8]. BP is a continuous variable that is positively correlated with cardiovascular risk across the entire $\mathrm{BP}$ range $[9,10]$. Race/ethnicity is another factor associated with differences in the prevalence of hypertension and the degree of arterial stiffness associated with high BP in children $[11,12]$. Thus, it is prudent to have population-specific 
evaluation of childhood BP and its associated factors for the full range of BP levels.

Health behaviours established in childhood tend to continue into adulthood. Most studies support the beneficial effect of physical activity (PA) in lowering BP in children [13,14], although unfavourable effects of moderate to vigorous intensity $\mathrm{PA}$ on $\mathrm{BP}$ have also been reported $[15,16]$. Family history of hypertension $(\mathrm{FHH})$ is a particularly important factor associated with high BP risk and its influence on BP occurs well before adolescence [17]. Although FHH cannot be modified, we do not yet know if children genetically predisposed to hypertension respond differently to excess body weight or other factors with regard to their BP. Furthermore, while socioeconomic inequalities are linked to childhood obesity in western developed countries [18], there are no reports on their impact on BP among children.

Several studies have reported on the prevalence of hypertension and pre-hypertension in Canadian children, but results are inconsistent [2,3]. Because of $\mathrm{BP}$ variability and suboptimal BP measurements, guidelines for minimum standards for surveys measuring BP were developed in Canada [19]. The Canadian Health Measures Survey (CHMS) is the first national survey to measure BP using these guidelines [20]. The goal of our study was to evaluate the independent effects of obesity, $\mathrm{PA}, \mathrm{FHH}$ and socioeconomic status (SES) on systolic BP (SBP) and diastolic BP (DBP) according to age and gender in a nationally representative sample of children and adolescents.

\section{Methods}

We used cross-sectional data from the CHMS, cycle 1, 2007-2009, a complex sampling survey designed to collect data on self-reported and direct measures of health and wellness from a representative sample of approximately 5600 Canadians aged 6 to 79 years. The CHMS covers approximately $96.3 \%$ of the Canadian population living in private dwellings in all ten provinces and three territories, but excludes those living on reserves and certain remote areas, institutional residents and full-time members of the Canadian Forces. Health Canada's Research Ethics Board reviewed and approved all processes and protocols for cycle 1 of the CHMS. Informed consent was obtained from all participants before starting any study procedures. Overall, the combined response rate was $51.7 \%$ for cycle 1 of the CHMS [20].

The CHMS cycle 1 included data for 1878 participants aged 6 to 17 years. For our purposes, we excluded 7 respondents missing BP measures, 2 missing BMI measures, and one being treated with hypertension medication. All study respondents were cross-tabulated for conditions that are the primary causes of BP elevation; one reported having diabetes mellitus type 1 and one other diabetes mellitus type 2; 11 reported congenital heart disease; and 4 reported kidney dysfunction or disease. We also excluded them from our analyses. Two participants who reported having hypertension but were not being treated with medications were retained. After an initial exploration of the data, we also excluded one 9-year-old boy whose BP was 173/127 $\mathrm{mmHg}$, for which an underlying condition was suspected. Thus, the final analyses included data for 1850 participants.

The survey consisted of a personal household interview followed by a physical examination at a mobile examination center within 2 days to 6 weeks of the interview. The household interview included a questionnaire about general demographic information and an in-depth health questionnaire. Parents/guardians answered all the applicable household questions for participants aged 6 to 13 years and, with assistance from children responded to questions about, for example, participation in physical activity during schools hours. Participants aged between 14 and 17 years answered all questions on their own.

Standing height and weight were measured and used to calculate BMI (weight [kilograms] divided by height [meters] squared). Age- and sex-adjusted BMI z-scores (BMIZ) were calculated based on World Health Organization (WHO) child growth charts [21]. According to $\mathrm{WHO}$, obesity is defined as a BMIZ that is more than two standard deviations (SDs) above the mean $(\approx$ $97.7^{\text {th }}$ percentile) and overweight as a BMIZ between one and two SDs above the mean $\left(\approx 84^{\text {th }}\right.$ to $97.7^{\text {th }}$ percentile).

Participants' resting BP was measured according to the new protocol for standard BP measurements in surveys [19]. Participants were invited to wait in a quiet and comfortable environment for at least 5 minutes before the measurement. BP was measured using an automated BP cuff (BpTRU) on the right arm with a cuff size suitable for the arm circumference. Six BP readings were taken with a clinically validated oscillometric device BpTRU $^{\text {TM }}$ BP-300, BpTRU ${ }^{\text {TM }}$ Medical Devices Ltd., Coquitlam, British Columbia) at 1-minute intervals, with $\mathrm{BP}$ determined as the average of the last 5 measurements. Heart rate was measured in beats per minute (bpm) with each BP measurement and averaged using the last 5 measurements. BP was measured manually only when inconsistency was related to high variability or too many errors, which occurred in fewer than $1 \%$ of cases. More detailed information on BP measurement in this survey can be found elsewhere [22].

We calculated age-, sex- and height-adjusted SBP zscores (SBPZ) and DBP $\mathrm{z}$-scores (DBPZ) using the US reference data [7]. We defined systolic or diastolic hypertension as SBPZ or DBPZ at or above the $95^{\text {th }}$ percentile. Pre-hypertension was defined as SBPZ or DBPZ 
between the $90^{\text {th }}$ and $95^{\text {th }}$ percentile or as for adults ( $\geq 120 / 80 \mathrm{mmHg}$ ).

The PA model for adults was adopted for adolescents aged 12 to 17 years [23]. Survey participants or their parents were asked about the type, frequency and duration of PA in the past 3 months during leisure time and at school. Energy expenditure (EE) was calculated using the frequency and duration per session of the PA as well as metabolic equivalents (MET) value of the activity. Calculated total daily EE values were used to develop a PA index: active, moderately active, and inactive. The PA of children aged 6 to 11 years was determined from the answers given to the question "Over a typical or usual week, on how many days was he/she physically active for a total of at least 60 minutes per day?" If the answer was " 4 days or more", the child was regarded as physically active; otherwise, the child was considered inactive.

We determined $\mathrm{FHH}$ from answers to the questions "Has anyone in your immediate family ever had high BP, excluding during pregnancy?" and "What is the youngest age at which a member of your immediate family was first diagnosed with high BP?" Participants who answered "Yes" to the former and reported that age at diagnosis was less than 60 years were considered to have an FHH.

We determined the highest education achieved by adult members of the household and dichotomized this based on whether at least one adult had completed postsecondary education. Household income was categorized into two groups (low, middle or high) based on the total family income from all sources and the number of people in the household; a third category was created for those with data missing on this variable. We defined ethnicity as whites and non-whites including Aboriginals living off reserves. Children aged 12 years and older were asked about cigarette smoking.

Because BP may increase substantially with the onset of puberty and between sexes [24], we stratified analyses for children (6 to 11 years) and adolescents (12 to 17 years), and for boys and girls. Associations of SBPZ or DBPZ with overweight and obesity, PA, FHH, education and income were estimated simultaneously using multivariate linear regression models, controlling for covariates - age and heart rate. Variables of ethnicity and cigarette smoking (adolescents only) were initially included in the models, but dropped later because they led no changes to the results. Another consideration in model construction was the 11 degrees of freedom requirement in statistical analysis, which restricts the number of parameters that can be entered into a model to 10. To evaluate the possible interactions between BMIZ and $\mathrm{FHH}$ on $\mathrm{BPZ}$, we added an interaction term for BMIZ and FHH to the full regression model. To evaluate the potentially varying effects of BMIZ on BPZ with respect to normal weight, overweight and obesity, we stratified analyses according to BMI category and performed multivariate linear regressions within each stratum. We were not able to carry out subgroup analysis for each stratum because of limited sample size.

The bootstrap method, which takes into account the complex survey design, was used to estimate standard errors, coefficients of variation and confidence intervals for means, proportions and coefficients of regression parameters. Because of restricted primary sampling units, Statistics Canada requires that $11 d f$ be applied to all the variance estimation with bootstrap method. Statistical significance in all analyses was defined as a $\mathrm{p}$ value $<0.05$. The analyses were performed using SAS Enterprise Guide 4 software (SAS Institute Inc.) and Bootvar 3.2 SAS version (Statistics Canada; www.statcan.gc.ca/rdc-cdr/bootvar_sas-eng.htm).

\section{Results}

\section{Population characteristics}

Overall, both mean SBP and DBP were markedly higher in adolescents (98.7 $\mathrm{mmHg}$ and $62.5 \mathrm{mmHg}$, respectively) than in children (93.2 and $60.5 \mathrm{mmHg}$ ) (Table 1). Mean SBPZ was -0.7 (95\% CI, $-0.75,-0.65)$ in children and -1.2 (95\% CI, -1.38,-1.08) in adolescents, suggesting lower SBP for Canadian children compared to US counterparts. Mean DBPZ in children, 0.07 (95\% CI, 0.01,0.13) was higher than US children, mean DBPZ in adolescents, -0.22 (95\% CI, $-0.34,-0.10)$ was lower than US adolescents. The prevalence of hypertension was less than $1 \%$, and the prevalence of pre-hypertension was about $2.2 \%$. More than $30 \%$ of young people were either overweight or obese (13\% of children and $15 \%$ of adolescents were obese, while another $20 \%$ of children and $16 \%$ of adolescents were overweight). A majority of children (83.6\%) and just over half of adolescents (55.2\%) reported being physically active, while $13.9 \%$ of children and $20.5 \%$ of adolescents reported having FHH. About $7 \%$ of participants were from low-income families, and at least one parent of over $70 \%$ of study participants had post-secondary education. Around three-quarters (75.5 \%) of study subjects were white, and $6.9 \%$ of adolescents reported smoking cigarettes daily.

\section{Factors associated with increasing SBP and DBP}

Table 2 shows the associations of interested variables with SBPZ and DBPZ in children. BMIZ was significantly associated with SBPZ in young girls $(\beta=.09 ; p=.02)$. Every 1-unit increase in BMIZ in young girls is associated with higher SBPZ by .09SD, equivalent to $\sim .9$ $\mathrm{mmHg}$ higher SBP (not shown in the table). When categorized BMI were used in the model, higher SBPZ were found for overweight $(\beta=.20 ; p=.04)$ and obese $(\beta=.34$; $p=.004$ ) young girls compared with normal weight young girls. Obesity in young girls was associated with $\sim 3.5 \mathrm{mmHg}$ higher SBP. Neither BMIZ nor being obese was associated with DBPZ in either sex. FHH was 
Table 1 Characteristics of Canadian children and adolescents in the Canadian Health measures Survey, 2007-2009

\begin{tabular}{|c|c|c|c|c|c|c|}
\hline & \multicolumn{6}{|c|}{ Age, years } \\
\hline & \multicolumn{3}{|c|}{6 to $11(n=1058)$} & \multicolumn{3}{|c|}{12 to $17(n=792)$} \\
\hline & $n$ & Mean or $\%$ & $95 \% \mathrm{Cl}$ & $n$ & Mean or $\%$ & $95 \% \mathrm{Cl}$ \\
\hline Boys, n (\%) & 531 & 50.5 & $49.7,51.4$ & 416 & 54.2 & $51.9,56.5$ \\
\hline Mean systolic blood pressure (mmHg) & 1058 & 93.2 & $92.4,93.9$ & 792 & 98.7 & $97.0,100.3$ \\
\hline Mean diastolic blood pressure (mmHg) & 1058 & 60.5 & $59.7,61.4$ & 792 & 62.5 & $61.2,63.9$ \\
\hline Mean systolic blood pressure z-scores & 1058 & -0.70 & $-0.75,-0.65$ & 792 & -1.20 & $-1.38,-1.08$ \\
\hline Mean diastolic blood pressure z-scores & 1058 & 0.07 & $0.01,0.13$ & 792 & $-0.22^{e}$ & $-0.34,-0.10$ \\
\hline Mean heart rate (bpm) & 1058 & 75 & 74,77 & 792 & 80 & 78,81 \\
\hline Mean body mass index $\left(\mathrm{kg} / \mathrm{m}^{2}\right)$ & 1058 & 17.8 & $17.6,18.0$ & 792 & 22.0 & $21.1,23.0$ \\
\hline Mean body mass index z-scores (BMIZ) & 1058 & 0.51 & $0.41,0.61$ & 792 & $0.47^{\mathrm{e}}$ & $0.22,0.73$ \\
\hline \multicolumn{7}{|l|}{ Body mass index category, $\mathrm{n}(\%)$} \\
\hline Normal weight (BMIZ < 84 percentile) & 733 & 67 & $63.2,70.7$ & 558 & 69.2 & $61.1,77.3$ \\
\hline Overweight (84 $\leq$ BMIZ $<97.7$ percentile) & 195 & 20.2 & $14.9,25.4$ & 143 & 15.8 & $11.6,19.9$ \\
\hline Obese (BMIZ $\geq 97.7$ percentile) & 131 & 12.9 & $9.9,15.8$ & 91 & $15.1^{e}$ & $8.6,21.6$ \\
\hline Physically active, n (\%) & 888 & 83.6 & $80.5,86.6$ & 424 & 55.2 & $49.3,61.2$ \\
\hline Family history of hypertension, n (\%) & 161 & 13.9 & $11.2,16.5$ & 173 & 20.5 & $16.8,24.2$ \\
\hline Low family income, n (\%) & 74 & $6.9^{e}$ & $3.6,10.2$ & 43 & $7.0^{e}$ & $3.2,10.8$ \\
\hline Post-secondary educated parents, n (\%) & 856 & 79.9 & $74.2,85.6$ & 605 & 73.1 & $65.5,80.8$ \\
\hline Ethnicity - whites, n (\%) & 814 & 75.4 & $62.0,88.7$ & 635 & 75.6 & $65.6,85.6$ \\
\hline Daily smoking, n (\%) & - & - & - & 53 & $6.9^{e}$ & $2.1,11.7$ \\
\hline
\end{tabular}

Mean and proportion (\%) were estimated using bootstrap method; $\mathrm{Cl}$, confidence interval.

e, CV coefficient of variation of $16.6 \%-33.3 \%$, interpret with caution.

positively associated with increases in both SBPZ $(\beta=.31)$ and DBPZ $(\beta=.26)$ for young girls, equivalent to $\sim 3.6 \mathrm{mmHg}$ higher SBP and $\sim 3.1 \mathrm{mmHg}$ higher DBP, but not in young boys. As expected, young girls whose parents had post-secondary education had, on average lower SBPZ. However, low family income was significantly associated with lower SBPZ in young boys and lower DBPZ in young girls. Age was inversely associated with SBP and DBP in both young boys and girls. Heart rate was significantly associated with both SBP and DBP in children.

Table 3 shows the associations of interested variables with increasing SBPZ and DBPZ in adolescents. BMIZ was significantly associated with SBPZ in adolescent boys $(\beta=.22 ; p=.001)$. Every 1 -unit incremental increase in BMIZ in adolescent boys increased SBPZ by .22SD, equivalent to $\sim 2.4 \mathrm{mmHg}$ increase in SBP (not shown). Compared to normal weight adolescents, significantly higher SBPZ was observed among both obese adolescent boys and girls ( $\beta=.69$ and 0.74 , respectively, equivalent to $\sim 7.6 \mathrm{mmHg}$ and $\sim 7.7 \mathrm{mmHg}$ ). Obese adolescent boys also demonstrated markedly higher DBPZ $(\beta=.21 ; p=.04)$, equivalent to $\sim 2.8 \mathrm{mmHg}$ higher DBP. Compared to active PA, moderate PA was significantly associated with increases in both SBPZ and DBPZ in adolescent boys (SBPZ: $\beta=.34, p=.02$; DBPZ: $\beta=.38, p<.001$ ), equivalent to $\sim 3.9 \mathrm{mmHg}$ for SBP and $\sim 4.9 \mathrm{mmHg}$ for DBP. Moreover, $\mathrm{FHH}$ in adolescent boys was positively associated with both SBPZ and DBPZ (SBPZ: $\beta=.44, p=.009$; DBPZ: $\beta=.30, p=.02$ ), equivalent to $\sim 4.6 \mathrm{mmHg}$ for SBP and $\sim 3.1 \mathrm{mmHg}$ for DBP. Age was inversely associated with SBP and DBP in adolescent boys, whereas positive effect of age on DBP was observed for adolescent girls. Heart rate was positively associated with DBP in adolescents. Of note, the overall adjusted $R^{2}$ was estimated at 0.75 for SBP in adolescent boys, indicating that the variables included in the model explained three-quarters of BP variability in this population.

\section{Interaction by $\mathrm{BMI}$ and $\mathrm{FHH}$ on the association of $\mathrm{BMI}$ with BP}

We examined the interaction term between BMIZ and $\mathrm{FHH}$ in the multiple linear regression model for the whole sample. No statistical significance was found for this interaction term $(\beta=.005 ; p=.93)$.

\section{Differences in association between BP and BMI by BMI category}

We sought to determine whether the effect of BMI on BP varies among normal weight, overweight and obese children and adolescents. We found that BMI was neither associated with $\operatorname{SBP}(\beta=.03 ; p=.56)$, nor with $\mathrm{DBP}$ 
Table 2 Associations of systolic blood pressure (SBP) and diastolic blood pressure (DBP) with relevant variables in children (ages 6-11) according to gender, Canadian Health Measures Survey, 2007-2009

\begin{tabular}{|c|c|c|c|c|}
\hline & \multicolumn{2}{|c|}{ SBP z-scores } & \multicolumn{2}{|c|}{ DBP z-scores } \\
\hline & $\bar{\beta}$ & $p$ & $\bar{\beta}$ & $p$ \\
\hline \multicolumn{5}{|l|}{ Boys $(n=530)$} \\
\hline Body mass index category - Normal weight & 1 & & 1 & \\
\hline - Overweight & .07 & .36 & .07 & .29 \\
\hline - Obese & .21 & .15 & -.02 & .90 \\
\hline Heart rate & .01 & .009 & .02 & $<.001$ \\
\hline Family history of hypertension - No & 1 & & 1 & \\
\hline - Yes & .14 & .22 & .06 & .40 \\
\hline Physical activity - Active & 1 & & 1 & \\
\hline - Inactive & -.12 & .37 & -.11 & .34 \\
\hline Ages & -.05 & .02 & -.04 & .02 \\
\hline Family income - Middle or high & 1 & & 1 & \\
\hline - Low & -.19 & .02 & -.10 & .44 \\
\hline Parental post-secondary education - No & 1 & & 1 & \\
\hline - Yes & -.11 & .21 & -.10 & .36 \\
\hline$R^{2}$ & .13 & & .15 & \\
\hline \multicolumn{5}{|l|}{ Girls $(n=528)$} \\
\hline Body mass index category - Normal weight & 1 & & 1 & \\
\hline - Overweight & .20 & .04 & .03 & .74 \\
\hline - Obese & .34 & .004 & -.09 & .44 \\
\hline Heart rate & .02 & $<.001$ & .02 & $<.001$ \\
\hline Family history of hypertension - No & 1 & & 1 & \\
\hline - Yes & .31 & .008 & .26 & .03 \\
\hline Physical activity - Active & 1 & & 1 & \\
\hline - Inactive & -.003 & .96 & -.17 & .01 \\
\hline Ages & -.13 & $<.001$ & -.08 & .002 \\
\hline Family income - Middle or high & 1 & & 1 & \\
\hline - Low & -.23 & .10 & -.42 & $<.001$ \\
\hline Parental post-secondary education - No & 1 & & 1 & \\
\hline - Yes & -.17 & .02 & -.14 & .17 \\
\hline$R^{2}$ & .18 & & 14 & \\
\hline
\end{tabular}

Dependent variable: SBP z- scores or DBP z-scores. All variables in the left column of the table were independent variables, and their associations with SBP or DBP were simultaneously adjusted using multivariate linear regression models. $\beta$, coefficient of regression parameters; $p:<0.05$.

$(\beta=-.08 ; p=.07)$ in the normal weight group, nor in the overweight group (SBP: $\beta=.03, p=.89$; DBP: $\beta=-.22$, $p=.40)$. By contrast, there was a strong association of BMI with $\operatorname{SBP}(\beta=.33 ; p=.02)$, and a borderline association with DBP $(\beta=.24 ; p=.06)$ among obese group (Figure 1$)$.

\section{Discussion}

The current study examined the association of childhood $\mathrm{BP}$ and its determinants in a nationally representative sample of Canadian children and adolescents. We found that obesity was positively associated with SBP, but not with DBP (except in adolescent boys among whom obesity was associated with higher DBP). We observed that obese adolescents had an average of $7.6 \mathrm{mmHg}$ higher SBP than that of normal weight adolescents. BMI had the strongest effect on BP among obese children and adolescents. Less physically active adolescent boys had higher SBP $(3.9 \mathrm{mmHg})$ and DBP $(4.9 \mathrm{mmHg})$ than physically active boys. $\mathrm{FHH}$ in young girls and adolescent boys was strongly associated with increases in both SBP and DBP. Both family income and parental education played independent roles on BP in young children.

Based on the first national physical measures survey, we reported that the prevalence of childhood hypertension 
Table 3 Associations of systolic blood pressure (SBP) and diastolic blood pressure (DBP) with relevant variables in adolescents (ages 12-17) according to gender, Canadian Health Measures Survey, 2007-2009

\begin{tabular}{|c|c|c|c|c|}
\hline & \multicolumn{2}{|c|}{ SBP z-scores } & \multicolumn{2}{|c|}{ DBP z-scores } \\
\hline & $\beta$ & $p$ & $\beta$ & $p$ \\
\hline \multicolumn{5}{|l|}{ Boys $(n=416)$} \\
\hline Body mass index category - Normal weight & 1 & & 1 & \\
\hline - Overweight & .38 & .01 & .21 & .19 \\
\hline - Obese & 69 & $<.001$ & .21 & .04 \\
\hline Heart rate & .006 & .31 & .009 & .03 \\
\hline Family history of hypertension - No & 1 & & 1 & \\
\hline - Yes & .44 & .009 & .30 & .02 \\
\hline Physical activity - Active & 1 & & 1 & \\
\hline - Moderate active & .34 & .02 & .38 & $<.001$ \\
\hline - Inactive & .23 & .12 & .21 & .06 \\
\hline Ages & -.08 & .001 & -.07 & $<.001$ \\
\hline Parental post-secondary education - No & 1 & & 1 & \\
\hline - Yes & -.16 & .20 & -.09 & .39 \\
\hline$R^{2}$ & .75 & & .24 & \\
\hline \multicolumn{5}{|l|}{ Girls $(n=376)$} \\
\hline Body mass index category - Normal weight & 1 & & 1 & \\
\hline - Overweight & .09 & .52 & -.01 & .93 \\
\hline - Obese & .74 & $<.001$ & .17 & .19 \\
\hline Heart rate & .009 & .06 & .01 & .007 \\
\hline Family history of hypertension - No & 1 & & 1 & \\
\hline - Yes & .16 & .20 & .09 & .42 \\
\hline Physical activity - Active & 1 & & 1 & \\
\hline - Moderate active & .03 & .77 & -.06 & .61 \\
\hline - Inactive & -.10 & .35 & -.20 & .12 \\
\hline Ages & -.004 & .85 & .05 & .01 \\
\hline Parental post-secondary education - No & 1 & & 1 & \\
\hline - Yes & -.12 & .38 & -.07 & .51 \\
\hline$R^{2}$ & .18 & & .12 & \\
\hline
\end{tabular}

Dependent variable: SBP z- scores or DBP z-scores. All variables in the left column of the table were independent variables, and their associations with SBP or DBP were adjusted simultaneously using multivariate linear regression models. $\beta$, coefficient of regression parameters; $p:<0.05$.

and pre-hypertension was at 2-3\%, which is significantly lower than other Canadian studies, in which prevalence of hypertension was reported at $7.4 \%$ and $14 \%[2,3]$. However, it is difficult to compare across studies because of differences in age, study populations (i.e. rural resident) and variability in BP measurement methods. Our results do seem to be in line with those studies with repeated BP measurements [25,26], suggesting the importance of standardizing BP measures. Our observations that BMI or obesity is consistently associated with increasing SBP are consistent with a series of studies performed on various populations, though some studies also observed the effect of BMI on DBP $[2,6]$. The mechanism underlying the association between obesity and hypertension is poorly understood. Sorof et al. proposed that obesity-induced hypertension may be mediated in part by sympathetic nervous system hyperactivity, which is partly manifested by increased heart rate and BP variability [6]. This possibility is supported by our data that heart rate is positively associated with BP, especially among children, and that a significant difference in heart rate was observed in the obese compared with nonobese groups (data not shown). Most research has focused on SBP because it is a strong predictor of arterial stiffness and many other cardiovascular risks growing into adulthood [11]. Our results support the close association between SBP and obesity, reinforcing the importance of maintaining a healthy weight for optimal SBP during childhood. In addition to substantial increases 


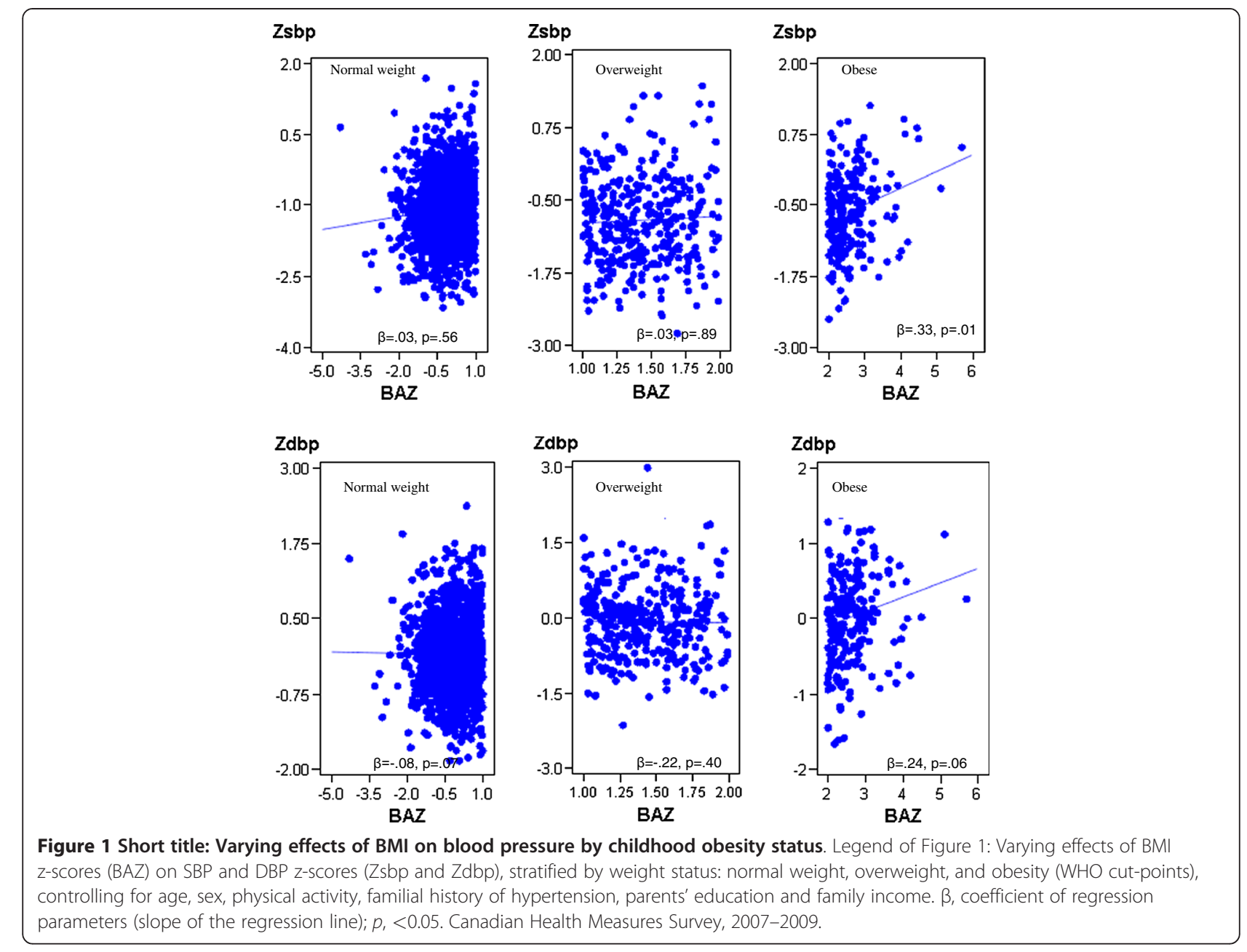

in SBP, we found markedly higher DBP in obese adolescent boys. This might be explained by evidence of early atherosclerosis at autopsy and ultrasound findings of the carotid artery, in which severely obese children, especial boys, display arterial stiffness and increased diastolic wall stress, indicating adverse changes in vascular health that could be the culprit for the increases in both SBP and DBP [27].

Furthermore, our results show that BMI has the strongest effect on BP among obese children and adolescents. Rosner et al. proposed that there may be a different effect of BMI on BP depending on the differing levels of fatness among various ethnic groups [12]. Our result are consistent with a recent study by $\mathrm{Tu}$ et al. who found that there is a marked intensification of the influence of adiposity on BP when children reach the categories of overweight and obese [28]. Moreover, the differing effect of BMI on both SBP and DBP may well be explained by some intervention studies. One such study by Rocchini et al. demonstrated that weight loss among obese adolescents changed the BP distribution from right skewed to no difference from the general population; however, they did not examine the effect on BP of weight loss among normal weight adolescents [29]. Further intervention research involving normal weight children would provide more insights into this discussion. While mechanisms underlying these differences are still being researched, recent evidence also indicates that the adipose tissuederived hormone, leptin, may be a potentially important mediator in linking the effect of adiposity on BP [28]. Our results do suggest that small reductions in weight among obese children may lead to reductions in their BP.

The present study observed an inverse association between physical activity and SBP and DBP in adolescent boys. A number of observational and intervention studies have investigated associations between $\mathrm{PA}$ and $\mathrm{BP}$ in children and adolescents. Kelley et al. combined the results of 12 randomized trials and concluded that PA leads to a small but statistically significant reduction in BP [30]. Using accelerometer-measured PA data from 
the NHANES, Mark et al. described a modest doseresponse relation of total PA and moderate-to-vigorous intensity PA with hypertension [31]. Leary et al. found a similar inverse association between total PA and SBP; however, when they compared the volume (duration and frequency) versus the intensity (vigorousness) of PA, they found that moderate to vigorous PA did not further reduce $\mathrm{BP}$ beyond the reduction achieved by a higher volume of $\mathrm{PA}$, suggesting the volume of PA may be more important than the intensity of PA in reducing BP $[15,16]$. Since PA levels defined in the CHMS did not distinguish between the volume and intensity of PA, we were unable to assess their individual effects on BP. Nevertheless, our study identified inactive or moderately active adolescent boys as at risk of increased SBP and DBP, suggesting that PA should be intensified to mediate the negative effect on BP of other risk factors, and be promoted particularly for girls as evidence suggests that girls are less likely to participate in moderate to vigorous PA than boys [32]. Current clinical guidelines recommend that vigorous PA such as participation in competitive sports should only be limited in the presence of uncontrolled stage 2 hypertension, which is above $99^{\text {th }}$ percentile for gender, age and height [7].

Research shows that both genetic and environmental factors significantly influence BP and the development of hypertension during childhood [17]. Our results show that the strength of associations between BMI and BP was not modified by the presence of FHH. What our cross-sectional study was unable to address, however, is whether children with $\mathrm{FHH}$ are more susceptible to elevated $\mathrm{BP}$ due to increased $\mathrm{BMI}$ or decreased $\mathrm{PA}$; more research is needed to explore effects of other risk factors in the presence of FHH so that targeted intervention can be designed for this genetically predisposed population. Interestingly, in future studies, increases in environmentally induced high blood pressure may serve to mask the association of blood pressure risk and genetic factors, for which $\mathrm{FHH}$ is a proxy.

Finally, the inverse relationship of post-secondary parental education with SBP in children, especially girls, is similar to previous findings in which BP in girls was related to socioeconomic variables in addition to anthropometric factors [33]. However, living in a low income family situation did not appear to increase risk of high BP, and was even associated with lower BP in children in this study. While some recent epidemiological studies from western developed countries have pointed that SES is inversely associated with childhood obesity, evidence on the relationship of SES with BP in childhood is limited [18]. Howe et al. in a recent study indicated important socioeconomic inequalities in obesity and cardiovascular risk factors including childhood
BP in children; however, the SES indicator used in their study was maternal education [34]. In Canada, findings on SES and its relation with childhood obesity are conflicting $[35,36]$. In fact, we have noticed in our data that prevalence of obesity is lower in the lowest income $(9.6 \%)$ than middle to high income groups (13.9\%). With ongoing data collection for the next cycle of the CHMS, more studies with larger survey samples, detailed information on SES and inclusion of more variables (i.e. dietary, psychological factors) are expected to verify our findings.

The present study has several strengths. First, the CHMS is a high quality survey with standardized BP measurement for a nationally representative sample. Second, the sample of children aged 6 to 17 years was large enough to achieve sufficient statistical power to assess the independent effects of multiple variables. Limitations of our study include the cross-sectional survey design, which does not allow us to make casual inferences about $\mathrm{BP}$ and its determinants. However, reverse causation is unlikely. Another limitation is related to oscillometric measured BP, which may have underestimated DBP when compared with the US reference data using auscultatory method. However, the accuracy of the device has been validated by the company for its use in adults and children, and checked regularly by comparing with a $\mathrm{T}$ tube connected mercury sphygmomanometer for comparable readings for SBP and DBP [37,38]. Finally, dietary factors have been important in the prevention and treatment of hypertension in adults, especially intakes of sodium and potassium $[39,40]$. However, measures estimating these nutrient intakes are no available in cycle 1 of the CHMS.

\section{Conclusions}

Due to the epidemic of childhood obesity in Canada and worldwide, increasing attention is being paid to the cardiovascular health of children and adolescents. Our study demonstrates the early impact of excess adiposity, insufficient PA, FHH and SES on BP and suggests that early interventions to reduce childhood obesity can, among other things, reduce exposure to prolonged blood pressure elevation and the future risk of cardiovascular disease. Guardians and/or physicians should pay close attention to weight gain, especially severe weight gain, in both children and adolescents. Public health planners and health care decision makers should consider the best means to ensure that children of all ages benefit from sufficient PA.

\section{Abbreviations}

BP: blood pressure; PA: physical activity; FHH: family history of hypertension; SES: socioeconomic status; SBP: systolic BP; DBP: diastolic BP; BMI: body mass index. 


\section{Competing interests}

The authors declare that they have no competing interests.

\section{Acknowledgements}

The Canadian Health Measures Survey was conducted by Statistics Canada in partnership with Health Canada and the Public Health Agency of Canada, with funding from the Canadian government.

\section{Author's contributions}

All authors were involved in designing the research, YS analysed the data, MDG advised on the analysis, MDG and HM gave advice and comments on interpretation, all authors were involved in writing the manuscript and all authors have read and approved the final manuscript.

Received: 19 December 2011 Accepted: 29 May 2012

Published: 29 May 2012

\section{References}

1. Shields M, Tremblay MS: Canadian childhood obesity estimates based on WHO, IOTF and CDC cut-points. Int J Pediatr Obes 2010, 5:265-273. 5-3.

2. Paradis G, Lambert M, O'Loughlin J, Lavallee C, Aubin J, Delvin E, Levy E, Hanley JA: Blood pressure and adiposity in children and adolescents. Circulation 2004, 110:1832-1838. 9-28.

3. Salvadori M, Sontrop JM, Garg AX, Truong J, Suri RS, Mahmud FH, Macnab $\mathrm{JJ}$, Clark WF: Elevated blood pressure in relation to overweight and obesity among children in a rural Canadian community. Pediatrics 2008, 122:e821-e827.

4. Bao W, Threefoot SA, Srinivasan SR, Berenson GS: Essential hypertension predicted by tracking of elevated blood pressure from childhood to adulthood: the Bogalusa Heart Study. Am J Hypertens 1995, 8:657-665.

5. Freedman DS, Dietz WH, Srinivasan SR, Berenson GS: The relation of overweight to cardiovascular risk factors among children and adolescents: the Bogalusa Heart Study. Pediatrics 1999, 103:1175-1182.

6. Sorof J, Daniels S: Obesity hypertension in children: a problem of epidemic proportions. Hypertension 2002, 40:441-447.

7. The fourth report on the diagnosis, evaluation, and treatment of high blood pressure in children and adolescents. Pediatrics 2004, 114:555576 .

8. Collins RT, Alpert BS: Pre-hypertension and hypertension in pediatrics: don't let the statistics hide the pathology. J Pediatr 2009, 155:165-169.

9. Malcolm DD, Burns TL, Mahoney LT, Lauer RM: Factors affecting left ventricular mass in childhood: the Muscatine Study. Pediatrics 1993, 92:703-709.

10. Trieber FA, McCaffrey F, Pflieger K, Raunikar RA, Strong WB, Davis H: Determinants of left ventricular mass in normotensive children. Am 」 Hypertens 1993, 6:505-513.

11. Li S, Chen W, Srinivasan SR, Berenson GS: Childhood blood pressure as a predictor of arterial stiffness in young adults: the bogalusa heart study. Hypertension 2004, 43:541-546.

12. Rosner B, Prineas R, Daniels SR, Loggie J: Blood pressure differences between blacks and whites in relation to body size among US children and adolescents. Am J Epidemiol 2000, 151:1007-1019. 5-15.

13. Andersen LB, Harro M, Sardinha LB, Froberg K, Ekelund U, Brage $S$, Anderssen SA: Physical activity and clustered cardiovascular risk in children: a cross-sectional study (The European Youth Heart Study). Lancet 2006, 368:299-304. 7-22

14. Gidding SS, Barton BA, Dorgan JA, Kimm SY, Kwiterovich PO, Lasser NL, Robson AM, Stevens VJ, Van HL, Simons-Morton DG: Higher self-reported physical activity is associated with lower systolic blood pressure: the Dietary Intervention Study in Childhood (DISC). Pediatrics 2006, 118:2388-2393.

15. Leary SD, Ness AR, Smith GD, Mattocks C, Deere K, Blair SN, Riddoch C: Physical activity and blood pressure in childhood: findings from a population-based study. Hypertension 2008, 51:92-98.

16. Tsioufis C, Kyvelou S, Tsiachris D, Tolis P, Hararis G, Koufakis N, Psaltopoulou T, Panagiotakos D, Kokkinos P, Stefanadis C: Relation between physical activity and blood pressure levels in young Greek adolescents: the Leontio Lyceum Study. Eur J Public Health 2011, 21:63-68.
17. Munger RG, Prineas RJ, Gomez-Marin O: Persistent elevation of blood pressure among children with a family history of hypertension: the Minneapolis Children's Blood Pressure Study. J Hypertens 1988, 6:647653.

18. Shrewsbury V, Wardle J: Socioeconomic status and adiposity in childhood: a systematic review of cross-sectional studies 1990-2005. Obesity (Silver Spring) 2008, 16:275-284.

19. Campbell NR, Joffres MR, McKay DW: Hypertension surveillance in Canada: minimum standards for assessing blood pressure in surveys. Can J Public Health 2005, 96:217-220.

20. Tremblay M, Wolfson M, Gorber SC: Canadian Health Measures Survey: rationale, background and overview. Health Rep 2007, 18(Suppl):7-20.

21. de OM, Onyango AW, Borghi E, Siyam A, Nishida C, Siekmann J: Development of a WHO growth reference for school-aged children and adolescents. Bull World Health Organ 2007, 85:660-667.

22. Bryan S, Saint-Pierre LM, Campbell N, Clarke J, Tremblay MS: Resting blood pressure and heart rate measurement in the Canadian Health Measures Survey, cycle 1. Health Rep 2010, 21:71-78.

23. Craig $\mathrm{CL}$, Marshall AL, Sjostrom M, Bauman AE, Booth ML, Ainsworth BE, Pratt M, Ekelund U, Yngve A, Sallis JF, Oja P: International physical activity questionnaire: 12-country reliability and validity. Med Sci Sports Exerc 2003, 35:1381-1395.

24. Dasgupta K, O'Loughlin J, Chen S, Karp I, Paradis G, Tremblay J, Hamet P, Pilote L: Emergence of sex differences in prevalence of high systolic blood pressure: analysis of a longitudinal adolescent cohort. Circulation 2006, 114:2663-2670. 12-12.

25. Chiolero A, Cachat F, Burnier M, Paccaud F, Bovet P: Prevalence of hypertension in schoolchildren based on repeated measurements and association with overweight. J Hypertens 2007, 25:2209-2217.

26. Moore WE, Eichner JE, Cohn EM, Thompson DM, Kobza CE, Abbott KE: Blood pressure screening of school children in a multiracial school district: the Healthy Kids Project. Am J Hypertens 2009, 22:351-356.

27. Woo KS, Chook P, Yu CW, Sung RY, Qiao M, Leung SS, Lam CW, Metreweli C, Celermajer DS: Overweight in children is associated with arterial endothelial dysfunction and intima-media thickening. Int J Obes Relat Metab Disord 2004, 28:852-857.

28. Tu W, Eckert GJ, Dimeglio LA, Yu Z, Jung J, Pratt JH: Intensified effect of adiposity on blood pressure in overweight and obese children. Hypertension 2011, 58:818-824.

29. Rocchini AP, Katch V, Anderson J, Hinderliter J, Becque D, Martin M, Marks C Blood pressure in obese adolescents: effect of weight loss. Pediatrics 1988, 82:16-23.

30. Kelley GA, Kelley KS, Tran ZV: The effects of exercise on resting blood pressure in children and adolescents: a meta-analysis of randomized controlled trials. Prev Cardiol 2003, 6:8-16.

31. Mark AE, Janssen I: Dose-response relation between physical activity and blood pressure in youth. Med Sci Sports Exerc 2008, 40:1007-1012.

32. Fairclough SJ, Boddy LM, Hackett AF, Stratton G: Associations between children's socioeconomic status, weight status, and sex, with screenbased sedentary behaviours and sport participation. Int J Pediatr Obes 2009, 4:299-305.

33. Macintyre $S$, Watt $G$, West $P$, Ecob R: Correlates of blood pressure in 15 year olds in the west of Scotland. J Epidemiol Community Health 1991, 45:143-147.

34. Howe LD, Galobardes B, Sattar N, Hingorani AD, Deanfield J, Ness AR, veySmith G, Lawlor DA: Are there socioeconomic inequalities in cardiovascular risk factors in childhood, and are they mediated by adiposity? Findings from a prospective cohort study. Int J Obes (Lond) 2010, 34:1149-1159.

35. Merchant AT, Dehghan M, Behnke-Cook D, Anand SS: Diet, physical activity, and adiposity in children in poor and rich neighbourhoods: a cross-sectional comparison. Nutr J 2007, 6:1

36. Veugelers PJ, Fitzgerald AL: Prevalence of and risk factors for childhood overweight and obesity. CMAJ 2005, 173:607-613. 9-13.

37. Mattu GS, Perry TL Jr, Wright JM: Comparison of the oscillometric blood pressure monitor (BPM-100(Beta) ) with the auscultatory mercury sphygmomanometer. Blood Press Monit 2001, 6:153-159.

38. Mattu GS, Heran BS, Wright JM: Comparison of the automated noninvasive oscillometric blood pressure monitor (BpTRU) with the auscultatory mercury sphygmomanometer in a paediatric population. Blood Press Monit 2004, 9:39-45. 
39. Appel $\amalg$, Brands MW, Daniels SR, Karanja N, Elmer PJ, Sacks FM: Dietary approaches to prevent and treat hypertension: a scientific statement from the American Heart Association. Hypertension 2006, 47:296-308.

40. Stamler R: Implications of the INTERSALT study. Hypertension 1991, 17: $|16-| 20$.

doi:10.1186/1471-2458-12-388

Cite this article as: Shi et al:: Increasing blood pressure and its associated factors in Canadian children and adolescents from the Canadian Health Measures Survey. BMC Public Health 2012 12:388.

Submit your next manuscript to BioMed Central and take full advantage of:

- Convenient online submission

- Thorough peer review

- No space constraints or color figure charges

- Immediate publication on acceptance

- Inclusion in PubMed, CAS, Scopus and Google Scholar

- Research which is freely available for redistribution 